\title{
Toward low-cost highly portable tactile displays with shape memory alloys
}

doi:10.1080/11762320701470517

\author{
R. Velázquez ${ }^{1}$, E. E. Pissaloux ${ }^{1}$, M. Hafez ${ }^{2}$ and J. Szewczyk ${ }^{1}$ \\ ${ }^{1}$ Université Pierre et Marie Curie - Paris 6, Laboratoire de Robotique de Paris, CNRS FRE 2507, \\ 92265 Fontenay aux Roses, France \\ ${ }^{2}$ CEA/LIST, 92265 Fontenay aux Roses, France
}

\begin{abstract}
This paper presents a new concept of low-cost, high-resolution, lightweight, compact and highly portable tactile display. The prototype consists of an array of $8 \times 8$ upward/downward independent moveable pins based on shape memory alloy (SMA) technology. Each tactile actuator consists of an antagonist arranged pair of miniature NiTi SMA helical springs capable of developing a $300 \mathrm{mN}$ pull force at $1.5 \mathrm{~Hz}$ bandwidth by using simple forced-air convection. The proposed concept allows the development of $200 \mathrm{~g}$ weight tactile instruments of compact dimensions which can be easily carried by a visually disabled user. A detailed technical description of the SMA active element, tactile actuator and tactile display is presented and discussed. Preliminary perceptual results confirm the effectiveness of the display on information transmission.
\end{abstract}

Key words: Tactile display, tactile actuator, antagonist behavior, NiTi helical spring, shape memory alloys.

\section{INTRODUCTION}

Tactile displays are devices meant to stimulate the skin, particularly on fingertips, to create sensations of contact. Such devices have for a long time been the domain of developments for visual information transmission for the visually impaired: reading (Braille characters) and some graphic/pictorial representation of $2 \mathrm{D}$ scenes. More recently, this field has expanded to involve potential uses in virtual reality, sensory augmentation, sensory substitution, tele-surgery, rehabilitation, robotics, game and entertainment among many others.

Typical displays involve arrays of upward/downward moveable pins as skin indentation mechanisms. Most devices commercially available are piezoelectric Braille displays. A Braille cell (eight contact pins), which represents a single character, costs around 40 USD and about 80 cells are typically used for displaying a line of text (NFB 2007).

Corresponding Author:

R. Velázquez

Université Pierre et Marie Curie - Paris 6

Laboratoire de Robotique de Paris, CNRS FRE 2507

92265 Fontenay aux Roses, France

Tel: +33146549079

Fax: +33146547299

Email: velázquez@robot.jussieu.fr
Cost is not the only drawback when further applications of a significant number of Braille cells are envisaged:

1) As piezoelectric technology is limited in stroke, mechanical amplifiers are needed. These are implemented as an additional burdensome module attached to the contact pins (Figure 1(a)). Displaying more than two lines of text at a time or 2D graphics becomes practically impossible: only two cells are possible to be arranged vertically (Figure 1(b)). More suitable devices for 2D tactile graphics have emerged but few have had an industrial development. A successful example is Metec's DMD12060 display based on miniature solenoids, which offers a $159 \times 59$ array for 70,000 USD (NFB 2007).

2) Portability in Braille text displays is quite relative. Nowadays it is defined by $1 \mathrm{~kg}$ weight devices of dimensions: $25 \times 15.5 \times 5 \mathrm{~cm}$ (HumanWare 2007).

Different research groups have developed laboratory prototypes seeking a more efficient implementation in terms of cost, performance and flexibility. Tactile devices previously developed explore servomotors (Wagner et al. 2002), electromagnetic coils (BenaliKhoudja et al. 2004), piezoelectric ceramics (Pasquero and Hayward 2003), pneumatics and thermo-pneumatics (Moy et al. 2002; Vidal et al. 2005), shape memory alloys (SMAs) (Taylor et al. 1997), polymer gels (Konyo et al. 2000) and electrorheological fluids (Taylor et al. 1998) as actuation 


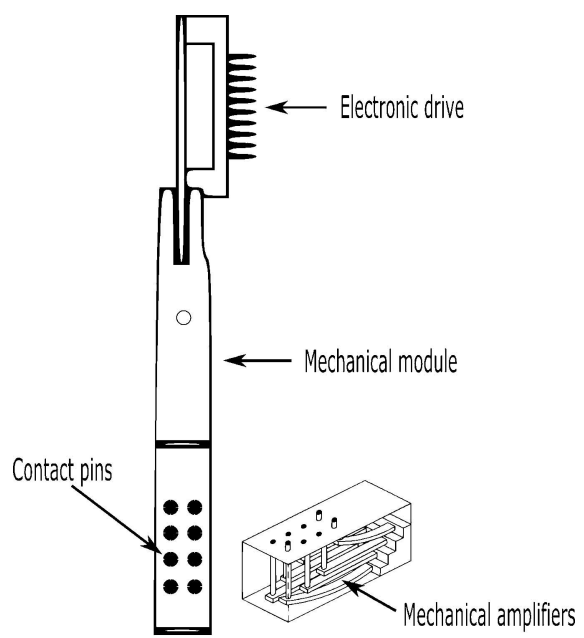

(a)

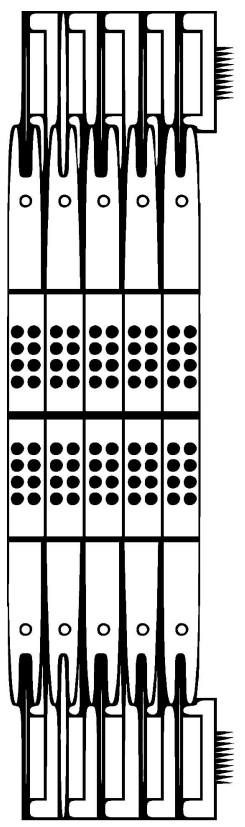

(b)

Figure 1 (a) Braille cell and (b) Braille cells only possible vertical arrangement.

technologies. Each of these approaches has its own advantages/disadvantages (the last especially heightened with scale reduction) and, due to the tradeoffs between bandwidth, integration capacity, scalability and cost, none of them has been found optimal for tactile displays.

SMA technology is one of the most promising candidates for high-resolution tactile displays. Advantages like simplicity, compactness, high power/weight ratio, noiseless operation, extremely high fatigue resistance to cyclic motion and low cost make them an interesting actuation principle. However, reported results (Taylor et al. 1997; Wellman et al. 1997; Brenner et al. 2000; Featherstone and Teh 2004) indicate small strokes due to a low 4 to $5 \%$ shape memory strain, high electrical heating current (2 A), slow

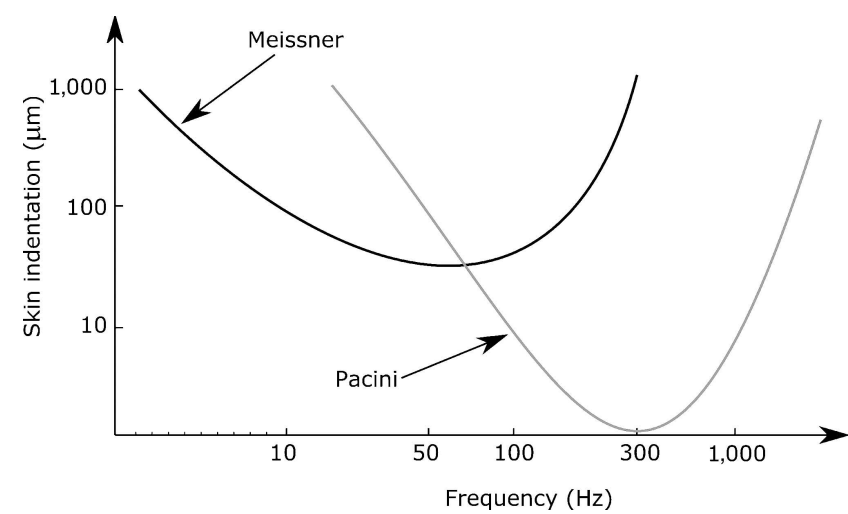

Figure 2 Skin indentation minimal detection thresholds as function of frequency, after Sekuler and Blake (2002).

response using forced-air convection (up to $1 \mathrm{~Hz}$ ) and the need of miniature mechanical blocking structures to keep the active position without power supply.

An SMA based miniature tactile actuator (Taxel (from tactile-pixel)): Term used for a tactile element) that seems to improve characteristics such as cost, scalability, integration capacity and overall performance is reported in this paper. Based on this approach, a new concept of low-cost, truly lightweight and highly portable tactile display has been developed.

The prototype consists of an array of 64 SMA based taxels featuring a $200 \mathrm{~g}$ weight device of compact dimensions $\left(8 \times 8 \times 8 \mathrm{~cm}^{3}\right)$, which can be easily carried by a visually disabled user. This concept intends to make possible highly-portable text-graphic Braille-like displays for 200 USD or less.

The rest of the paper is organized as follows: the second section presents a brief review of human tactile perception and the requirements for touch-stimulating devices. The third section introduces the SMA active element and evaluates its mechanical properties for actuation. The fourth section describes the taxel and its performance, while the fifth section presents and discusses the tactile display design concept, prototype and preliminary results on shape recognition. Finally, it concludes with main remarks and future work perspectives.

\section{GUIDELINES FOR TACTILE DISPLAYS: A PSYCHOPHYSIOLOGY APPROACH}

Four primary parameters are studied in relation to tactile stimulus generated by touch stimulating devices: skin indentation amplitude, frequency, spatial discrimination and applied force.

Physiology of touch indicates that mainly Meissner and Pacini skin mechanoreceptors are involved in hand feeling during object exploration. Figure 2 shows the relation between the amount of skin indentation and frequency for stimuli detection in these mechanoreceptors.

As seen, while Pacini cells are sensitive to high frequency vibration, Meissner ones are sensitive to low 
frequency touch stimuli. The tactile display envisaged intends to display information that represents a significant gradient in the skin surface and that remains static during exploration more than vibrating information. It seems then that stimulation of Meissner cells is more suitable for this application.

Concerning spatial discrimination of Meissner cells, a density of 140 per $\mathrm{cm}^{2}$ is usually found in fingertips. This corresponds to a $0.9 \mathrm{~mm}$ center-to-center spacing. However, this does not mean that we can actually perceive with this resolution. Human touch cannot perform discretely below a resolution suggested by a two-point discrimination threshold (TPDT). The TPDT is the minimum distance with which we can identify two points given in a simultaneous two-point contact (Geiger 1984). The TPDT on fingertips is 2 to $3 \mathrm{~mm}$, being $2.54 \mathrm{~mm}$ the standard TPDT adopted by Braille devices.

Concerning the contact force of fingers and palms in the exploratory process, a survey of psychophysical experimental data (Loomis 1981), indicates that a 50-100 $\mathrm{mN}$ force is applied during a fine-touch object exploration.

All the above data suggest that a tentatively correct Meissner stimulation device should integrate a large number of actuators with a $2.54 \mathrm{~mm}$ interspacing, an effective skin indentation of $0.7-1 \mathrm{~mm}$, stimuli frequencies of 1 to $3 \mathrm{~Hz}$ and a minimum delivered force of $100 \mathrm{mN}$.

\section{SHAPE MEMORY ALLOY ACTIVE ELEMENT}

Since their discovery in the late sixties, shape memory alloys (SMAs), especially the Nickel-Titanium (NiTi) one, have attracted much attention from research and industry for innovative applications, particularly as active elements of actuators. This success is based on their unique properties of superelasticity and shape memory effect (SME).

The SME in SMAs is the capability of recovering a predetermined shape upon heating. At low temperature martensite $(M)$ phase these alloys are quite malleable, thus they can be easily deformed into a new shape, which they retain. Upon heating, they return, in a high temperature austenite $(A)$ phase, to an original memorized shape.

Shape memory alloys can be formed into almost any shaped actuator. Most popular shapes are wire, spring, tubing, sheet and ribbon.

Experimental testing of NiTi SMA straight wires has revealed that stroke is limited to approximately $4 \%-5 \%$ of their original length. Compared to wires, springs do have a significantly higher recoverable strain. Impressive $300 \%$ strokes can easily be obtained using helical springs. However, as they perform in torsion instead of tension, they cannot develop the same force.

This paper suggests that SMA springs can be designed to exert significant forces for touch applications having at the same time stroke and compactness not offered by straight wires.

\section{Material}

A miniature NiTi helical spring was fabricated with trademark Flexinol wire with the following geometric characteristics: $200 \mu \mathrm{m}$ of wire diameter, $1.5 \mathrm{~mm}$ of spring outer diameter and 12 active coils. Its mass is $30 \mathrm{mg}$.

Energy dispersive X-ray (EDX) analysis confirmed its composition to be approximately $\mathrm{Ni}_{52} \mathrm{Ti}_{48}$. The helical spring shape was set by winding the wire tightly on a cylindrical mandrel (screw-like) and then heat-treating both wire and mandrel at $500^{\circ} \mathrm{C}$ for 5 minutes. Rapid cooling via water quench concluded the process (Figure 3 ) (Velazquez et al. 2006a).

\section{Evaluation of SMA thermomechanical behavior}

As aforementioned, the SME in SMAs is characterized by phase transformations thermally activated. These transformations lead to a thermomechanical behavior which, at a macroscopic level, determines the force and motion developed by the SMA element.

Considering the simple geometry of a helical spring, Tobushi and Tanaka (1991) have proposed an elastoplastic constitutive relation to predict its SMA load-deflection behavior. This relation suggests a stress-strain-temperature dependence which can be written as:

$$
P= \begin{cases}\frac{G d^{4}}{8 N D^{3}} \delta & \text { for } \quad \delta<\delta_{\mathrm{e}} \\ \frac{\pi \tau_{p} d^{3}}{6 D}\left[1-\frac{1}{4}\left(\frac{\pi N \tau_{p} D^{2}}{d G \delta}\right)^{3}\right] & \text { for } \quad \delta \geq \delta_{\mathrm{e}}\end{cases}
$$

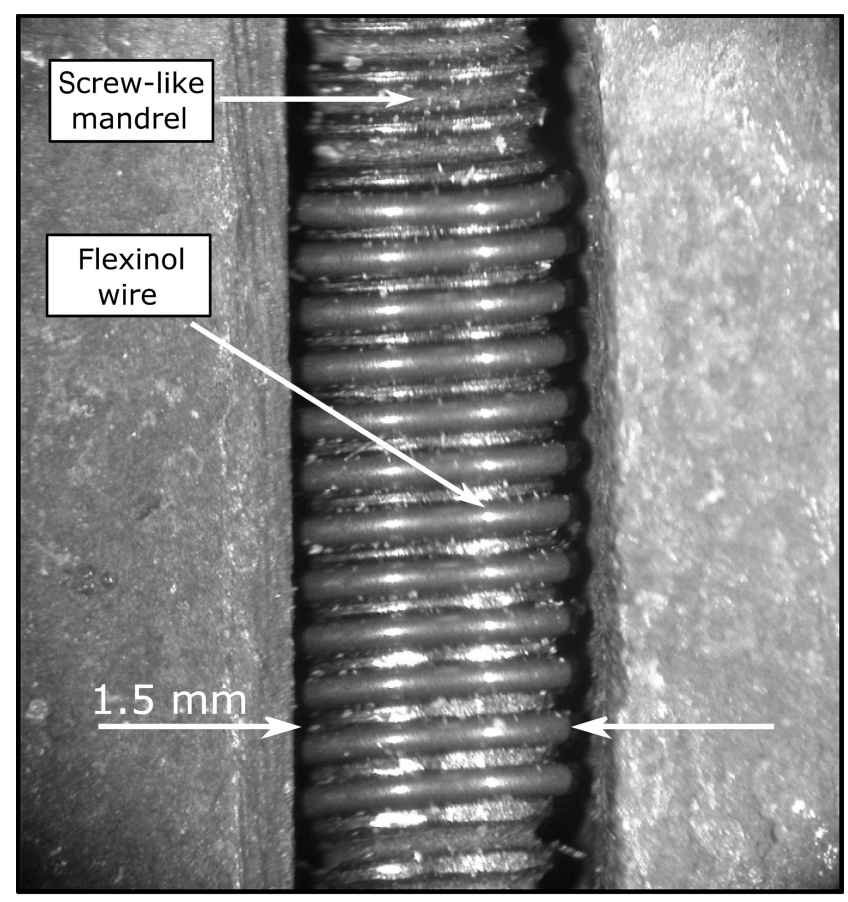

(a)

Figure 3 Fabrication procedure of an SMA helical spring: (a) constrained Flexinol wire on a mandrel and (b) helical shape after heat treatment. 


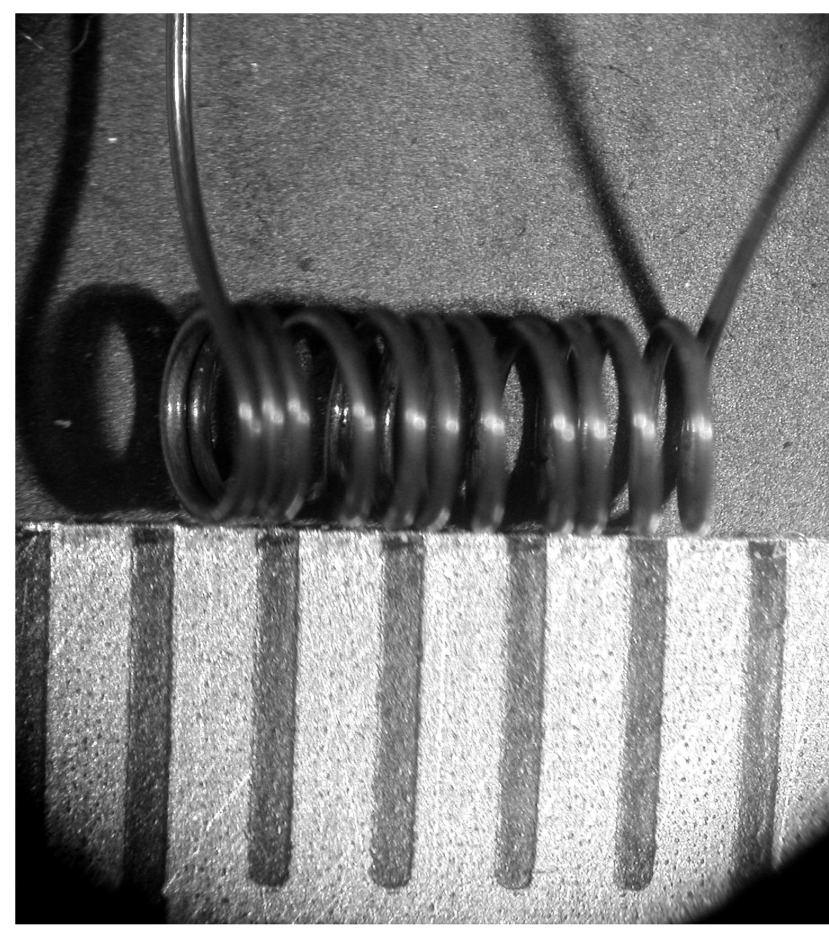

(b)

Figure 3 Continued

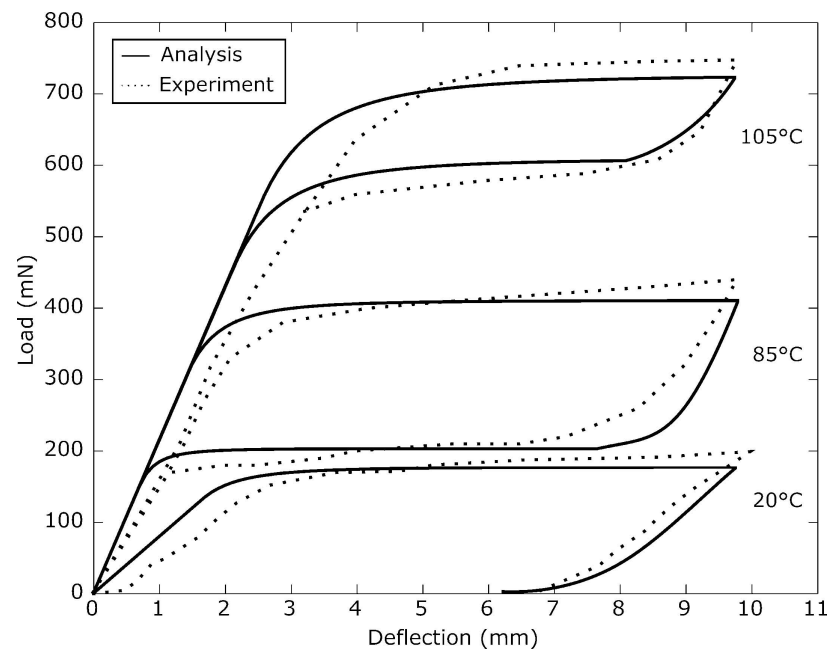

(a)

Figure 4 Deformation behavior of the SMA spring:

(a) load-deflection relations at constant temperatures $(20,85$ and $105^{\circ} \mathrm{C}$ ), (b) hysteresis due to R-phase and (c)

computational SMA behavior in the load-deflection-temperature space.

with:

$$
\delta_{e}=\frac{\pi D^{2} N \tau_{p}}{G d}
$$

and

$$
\tau_{p}= \begin{cases}c_{M}\left(T-M_{s}\right) & \text { for loading } \\ c_{A}\left(T-A_{s}\right) & \text { for unloading }\end{cases}
$$

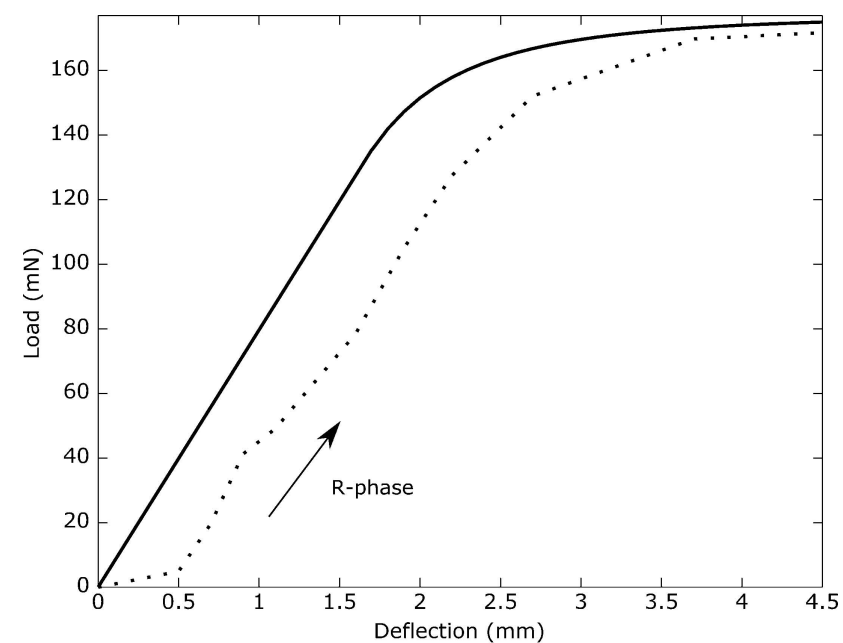

(b)

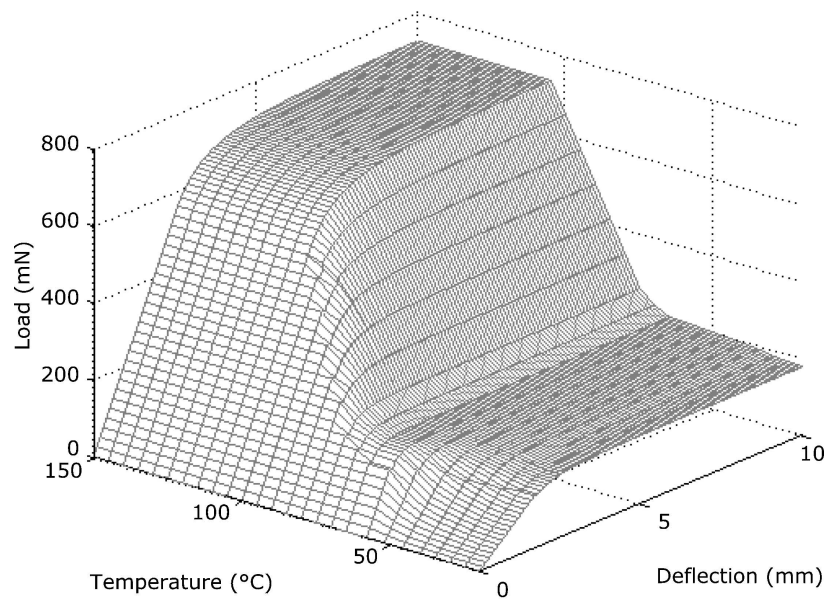

(c)

Figure 4 Continued

where $P$ is the load applied to the SMA spring, $\delta$ is the deflection induced by $P, d$ is the wire's diameter, $D$ is the mean spring diameter, $N$ is the number of active coils, $G$ is the shear modulus of elasticity, $\tau_{p}$ is the temperature dependent torsional stress, $\delta_{e}$ is the boundary of the elastic and plastic regions, $c_{m}, c_{a}$ are the material's constants which describe the transformation conditions and $A_{s}, M_{s}$ are the start temperatures for the $A$ and $M$ phase, respectively.

For NiTi, the experimental data in Tobushi and Tanaka (1991) indicate austenitic $G=28.2 \mathrm{GPa}$ and martensitic $G=10.5 \mathrm{GPa}$ and estimate $c_{m}=6.3 \mathrm{MPa} / \mathrm{K}$ and $c_{a}=$ $4.9 \mathrm{MPa} / \mathrm{K}$.

For the spring specimen fabricated, differential scanning calorimeter (DSC) tests determined that the stable transformation temperatures are $65,28,59,36,-3$ and $-37^{\circ} \mathrm{C}$ for $A_{f}, A_{s}, R_{s}, R_{f}, M_{s}$ and $M_{f}$, respectively (Velazquez et al. 2006a).

Geometrical parameters $d, D$ and $N$ were optimized using equation (1) so that the spring develops an appropriate force and stroke for touch applications.

Figure 4(a) compares the calculated and experimental load-deflection curves under various isothermal 

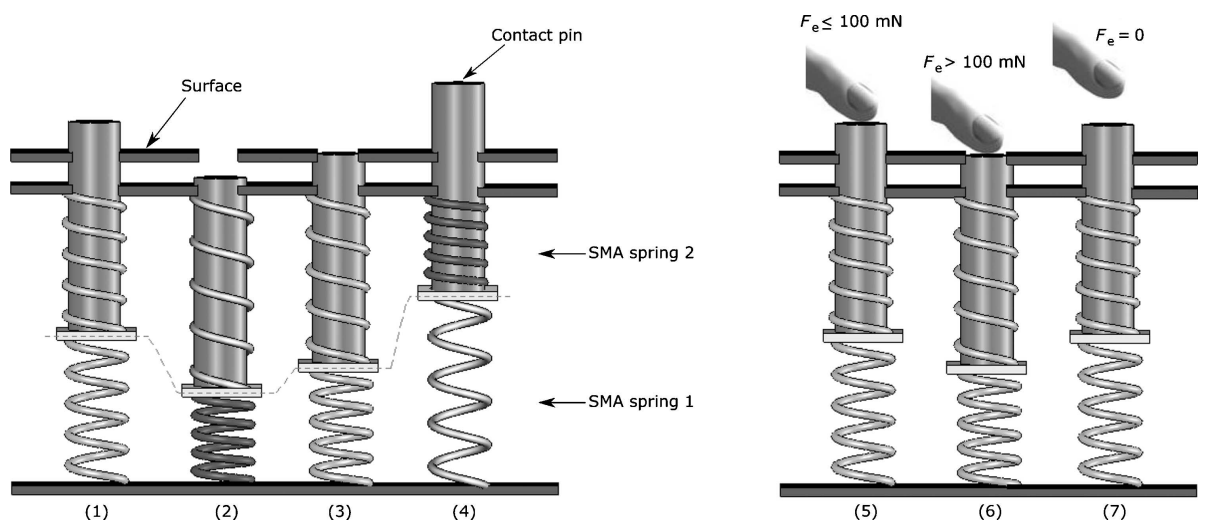

Figure 5 Principle of the SMA tactile actuator (taxel).

conditions for a maximum deflection of $10 \mathrm{~mm}$. Experimental loading-unloading results were obtained from tensile tests performed for each material phase independently, that is, pure austenitic and pure $\mathrm{R}$-phase under isothermal conditions $\left(20,85\right.$ and $\left.105^{\circ} \mathrm{C}\right)$.

As seen, numerical results well explain the spring's overall deformation behavior. The loading curves indicate that in order to induce a $10 \mathrm{~mm}$ deflection to the SMA spring, the necessary load to be applied is approximately $180 \mathrm{mN}$ at $20^{\circ} \mathrm{C}, 410 \mathrm{mN}$ at $85^{\circ} \mathrm{C}$ and $720 \mathrm{mN}$ at $105^{\circ} \mathrm{C}$. On the other hand, the unloading curves indicate the mechanical hysteresis of the SMA when the original configuration is being recovered. Note that for temperatures at or above the austenite state, the memory shape is perfectly recovered but not for $\mathrm{R}$-state ones.

A small mechanical hysteresis of $0.5 \mathrm{~mm}$ can be perceived when the spring is deformed at room temperature (Figure 4(b)). This effect is due to the R-phase. According to the DSC analysis, martensite phase takes place within the range -37 to $-3^{\circ} \mathrm{C}$. This means that, for actuation at room temperature, the M-transformation will never occur. The R-phase has similar macroscopic properties as the martensite phase and as the DSC test revealed, the R-phase offers the advantage of a shorter temperature hysteresis. For the purpose of this work, the R-phase will be considered as identical to the M-phase.

Figure 4(c) shows the phenomenological representation of the spring's SMA behavior in the load-deflectiontemperature space.

\section{TACTILE ACTUATOR}

SMAs can be used to design actuators that create linear motion. We propose a new SMA based electrically driven taxel. The idea behind the taxel simply consists of a pair of SMA springs configured in antagonist mode. The operation principle is shown in Figure 5.

At the initial position (1), the taxel's contact pin is raised. Both SMA springs are prestrained and in martensite phase, (2) when the SMA spring-1 is electrically heated, it recovers an austenitic compressed memorized shape that extends the SMA spring-2 and retracts the contact pin. The taxel is now in the lower position. (3) When the electrical current is disconnected, the temperature of the spring- 1 starts to decrease and so its rigidity. In consequence, the contact pin tends to rise. However, it will be demonstrated that it does not return to the initial position (pin raised); the lower position is still ensured. (4) To raise the pin again, the SMA spring-2 is activated. Upon cooling, the initial position will be reached.

Consider now the case when the surface is explored with the fingertips; (5) as seen in (1), the taxel's default configuration is when both SMA springs are in martensite phase and the contact pin is raised. This configuration must be able to withstand at least normal haptic exploration contact forces $(100 \mathrm{mN})$. (6) If the user applies a higher force (an intentionally violent touch), the contact pin will be retracted to surface level. (7) When the force is released, the contact pin naturally rises to recover its original configuration.

\section{SMA antagonist behavior}

Let us characterize the actuator's SMA antagonist behavior using a pair of SMA springs of geometric and thermomechanical characteristics described in the third section.

Consider both springs identically pre-strained (distance $O-\delta_{0}$ and $O^{\prime}-\delta_{0}$ in Figure 6(a)) in martensitic equilibrium point $\delta_{0}$ (Figure 6(a.1)). When the lower spring is heated, the new equilibrium point $B$ is defined by the intersection of its austenite curve and the upper spring's martensite one (Figure 6(a.2)). When cooling, the lower spring tends to recover its martensite characteristic at the same time that the upper one mechanically unloads.

Note that the equilibrium point does not follow the $B-\delta_{0}$ trajectory but the $B-D$ one (Figure 6(a.3)). The same phenomenon is observed when the upper spring is heated; it follows $\delta_{0}-A-C$ (or $D-A-C$ ) instead of $\delta_{0}-A-\delta_{0}$ (or $D-A$ $\left.\delta_{0}\right)$ (Figures 6(a.4) and 6(a.5)).

A more complete representation of the thermomechanical path followed by the equilibrium point is shown in Figure 6(b). Note that the initial position $\delta_{0}$ is not recovered due to the mechanic unloading characteristic of martensite. 

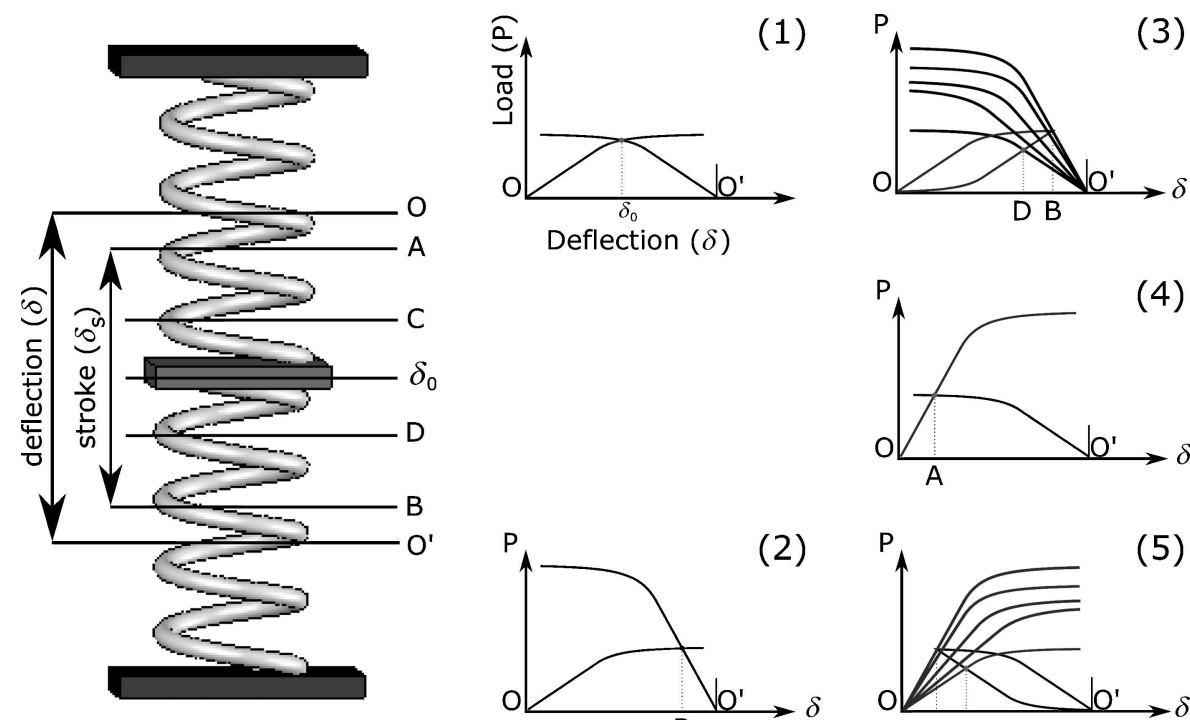

(3)
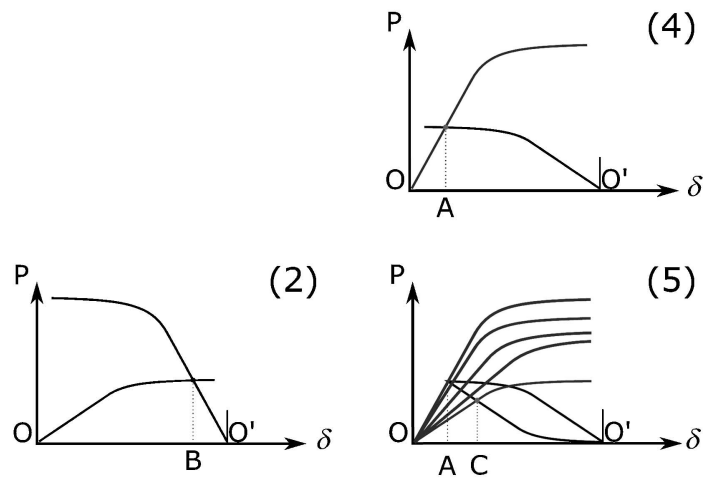

(a)

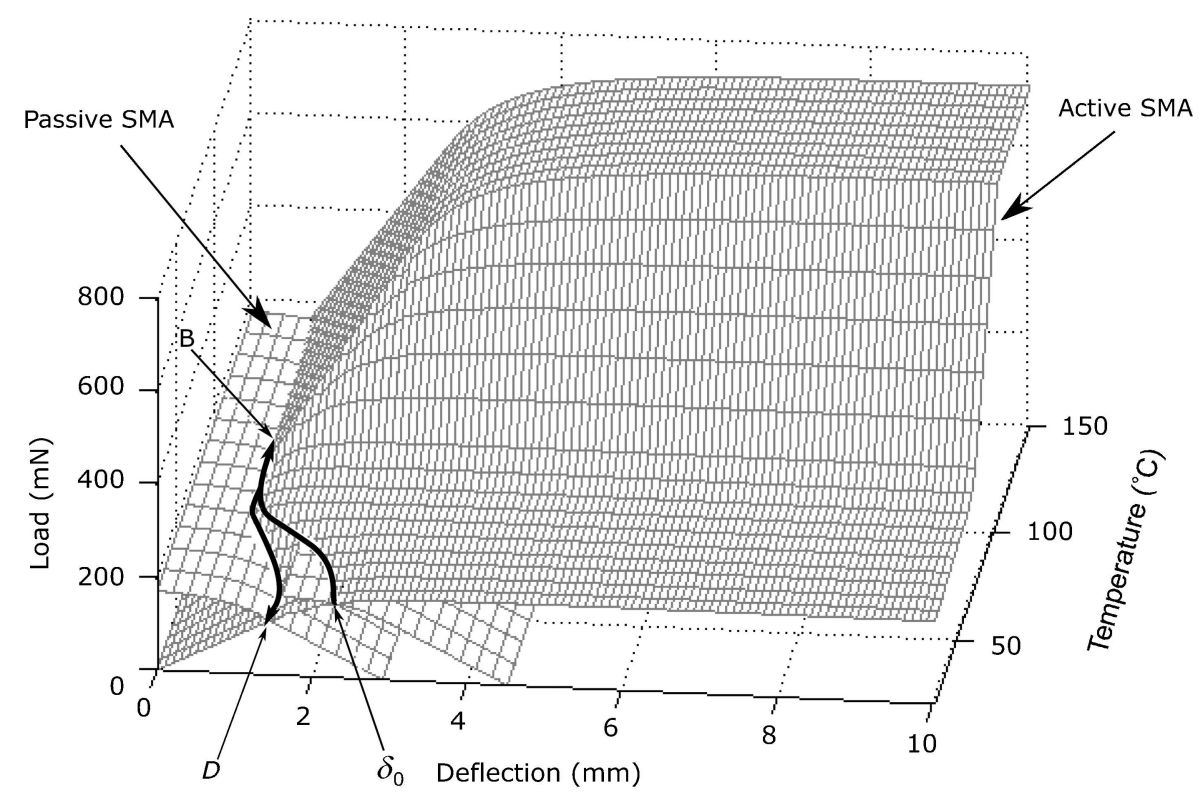

(b)

Figure 6 SMA antagonist principle: (a) the actuator's conceptual representation and load-deflection relations for a complete operating cycle. (b) Thermomechanical path performed by the actuator in the load-deflection-temperature space.

Let us analyze the case when an external force is applied to the system. Two situations can be predicted:

1) The force is applied during the austenitic state of the upper spring (Figure 7(a.1)). The superelasticity property appears in the active spring while the passive one follows an unloading behavior. Note that a $320 \mathrm{mN}$ force is needed to reach point $\delta_{0}$ (Figure 7(a.2)). When the external force is released, the active spring unloads by following its austenite characteristic as the passive one mechanically loads (Figure 7(a.3)).
Figure 7(a.4) shows this thermomechanical path in the load-deflection-temperature space. Note that the initial position $A$ is recovered in this case even though a nonreversible path is observed between $A-\delta_{0}$.

2) The force is applied during the martinsitic state of the upper spring (Figure 7(b.1)). Note that, while the upper spring follows a loading behavior, the passive one performs an unloading path. A $120 \mathrm{mN}$ force is required in this case to reach point $\delta_{0}$ (Figure 7(b.2)). When the external force is released, both springs mechanically unload by following their martensite characteristic (Figure 7(b.3)). Note that point $C$ is not recovered. 

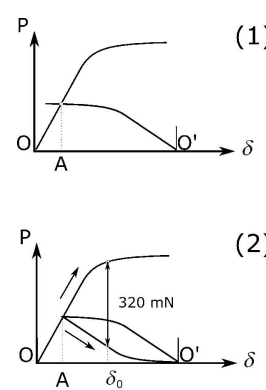

(2)

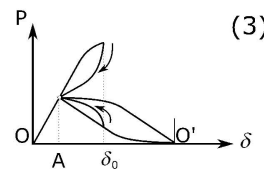

(3)

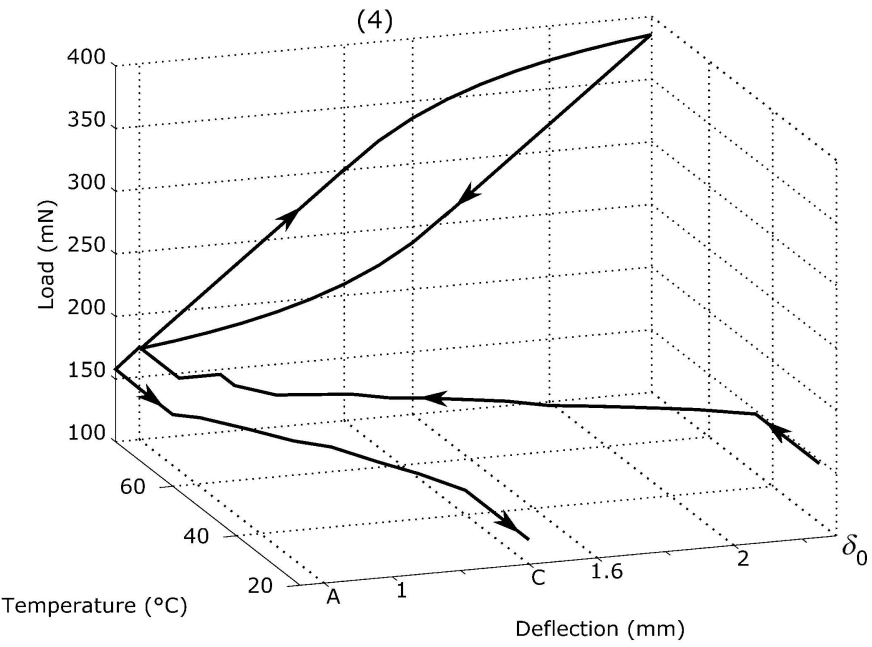

(a)
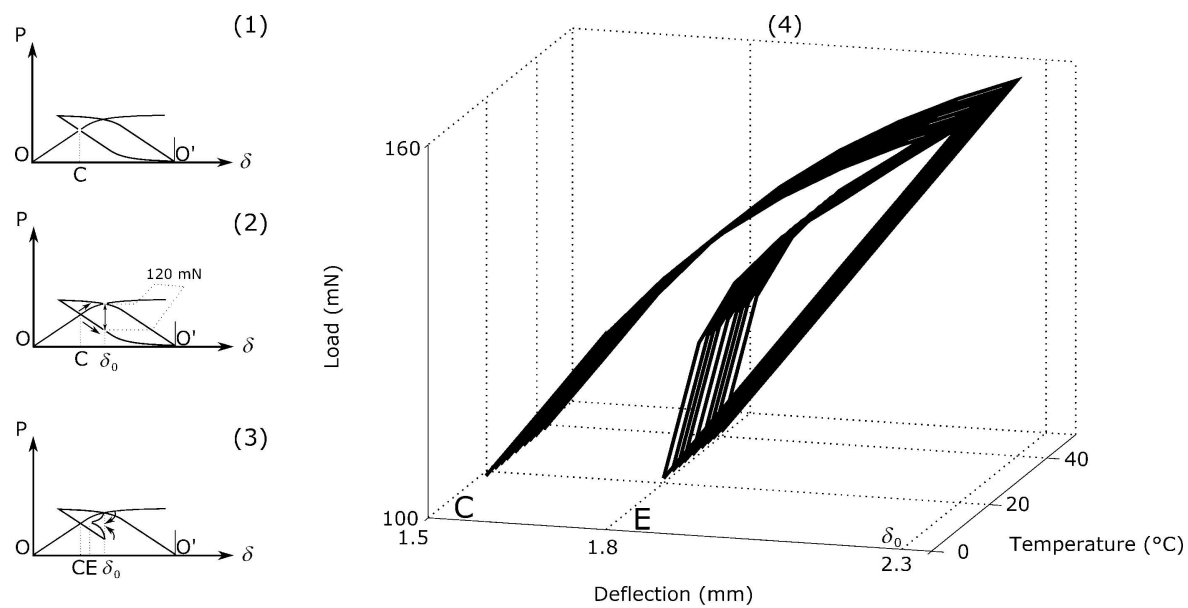

(b)

Figure 7 The upper spring's behavior face to an external force: (a) austenitic and (b) martensitic cases.

Figure 7(b.4) shows the load-deflection path performed for martensitic temperatures. Note that a new point $E$ appears after the force is released. For subsequent cycles, a $60 \mathrm{mN}$ force is required to reach $\delta_{0}$ from point $E$.

In conclusion, pre-stain $\delta_{0}$ must be carefully determined in order to calibrate the system and ensure that $B$ and $D$ positions will provide a lower taxel position while $A, C$ and $E$ will provide an upper one. Pre-straining both springs 2.3 $\mathrm{mm}$ at installation satisfies these requirements.

\section{Prototype and performance}

Figure 8 shows the prototype actuator built with an antagonist arranged pair of NiTi SMA helical springs (Velazquez et al. 2005). The actuator is of $1.5 \mathrm{~mm}$ diameter, $45 \mathrm{~mm}$ length and $150 \mathrm{mg}$ weight. Its laboratory cost is 2 USD.

Figure 9 compares the simulated and experimental relationships between force applied and taxel displacement during the process of surface exploration with the finger- tips. The theoretical modeling and experimentation show that the force response of the SMA antagonistic taxel, when an external force $F_{e}$ is applied, is actually defined by the difference between the curves characterizing the mechanical behavior of the springs.

Note that, while a $300 \mathrm{mN}$ force is needed to retract the taxel to surface level during the austenitic state of the upper spring (Figure 9(a)), a $102 \mathrm{mN}$ force is needed during its martinsitic state (Figure 9(b)).

The sequence in Figure 10 demonstrates the taxel's main concept and performance. It shows a set of eight taxels and their behavior in response to an external force. (1) The taxels' default configuration is pin raised and the antagonistic pair of SMAs in martensite phase. During exploration, (2) the taxels withstand normal contact forces but (3) higher ones may retract the pins to surface level. (4) When the force is released, the contact pins naturally rise to recover the original configuration. A broken line is drawn to better appreciate the position of the central mass at each time. 


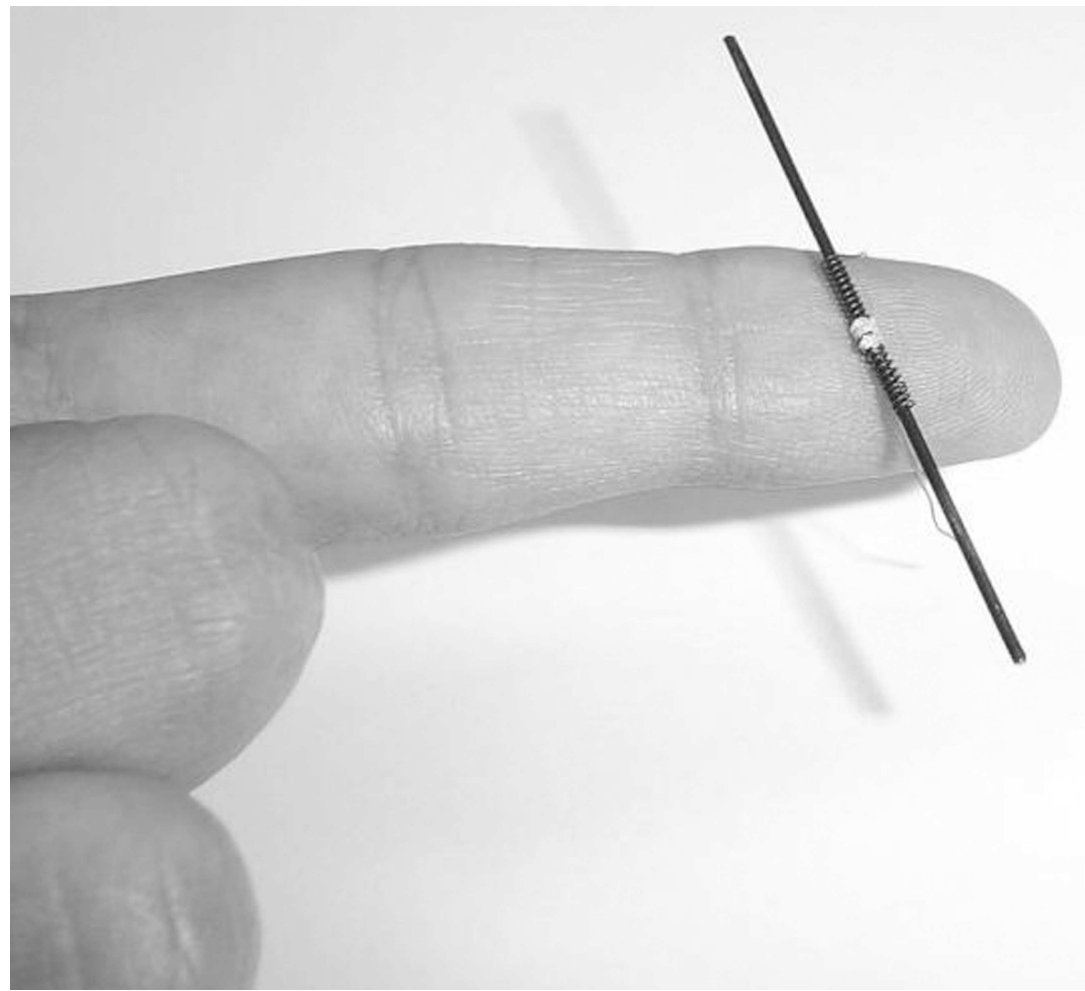

Figure 8 SMA based miniature tactile actuator.

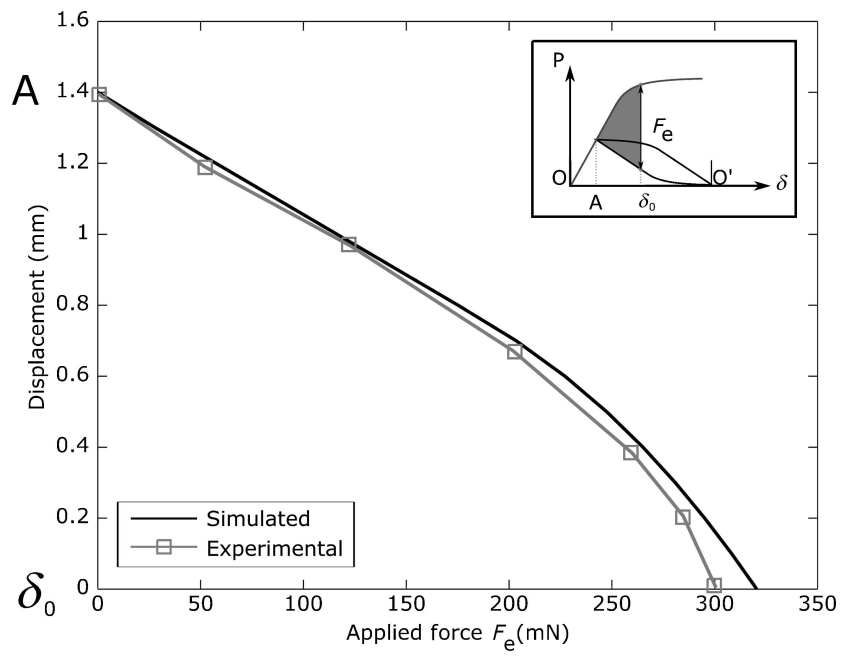

(a)

Figure 9 Effect of external force on the taxel's displacement: upper spring in (a) austenite and (b) martensite state.

To evaluate the taxel's bandwidth performance, an experimental setup was implemented as shown in Figure 11(a). Note that one of the constraints of the antagonist actuator is that at no time should both SMA springs be driving the system. For this purpose, an inverse switch was used to route the input and alternatively activate springs 1 and 2 .

Plots 11(a.1) and (a.2) show the position tracking response of the taxel, under no-load conditions, to 0.27

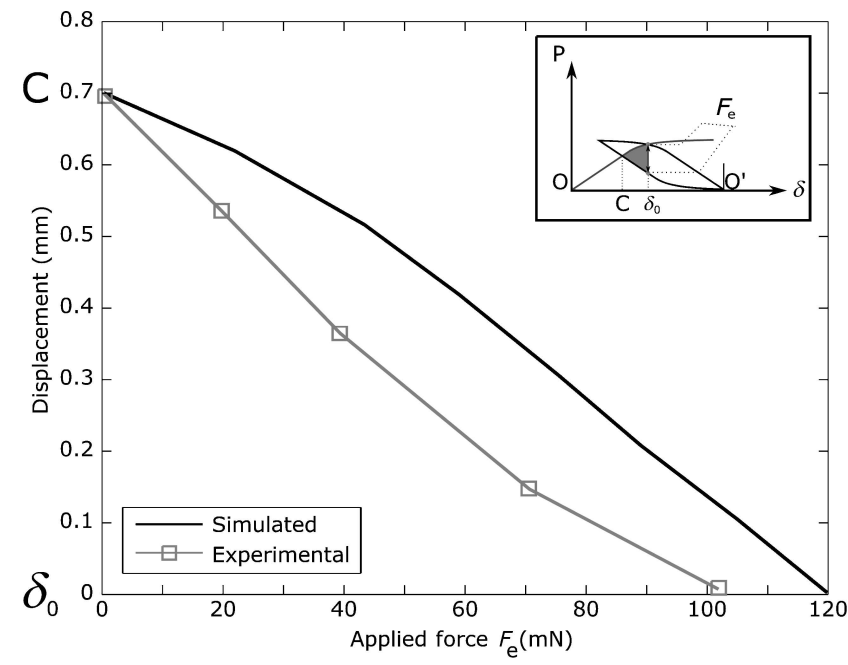

(b)

Figure 9 Continued

and $0.37 \mathrm{~Hz}$ square wave power signals, respectively. Note that, as frequency increases, the actuator's response becomes problematic: the cooling rate decreases significantly enough to produce no effect on both SMA springs. Soon, the actuator goes into saturation.

From this experience, it can be concluded that the control input is unilateral: it is always possible to apply more electrical current to produce a faster response but cooling is due exclusively to convective heat transfer to 


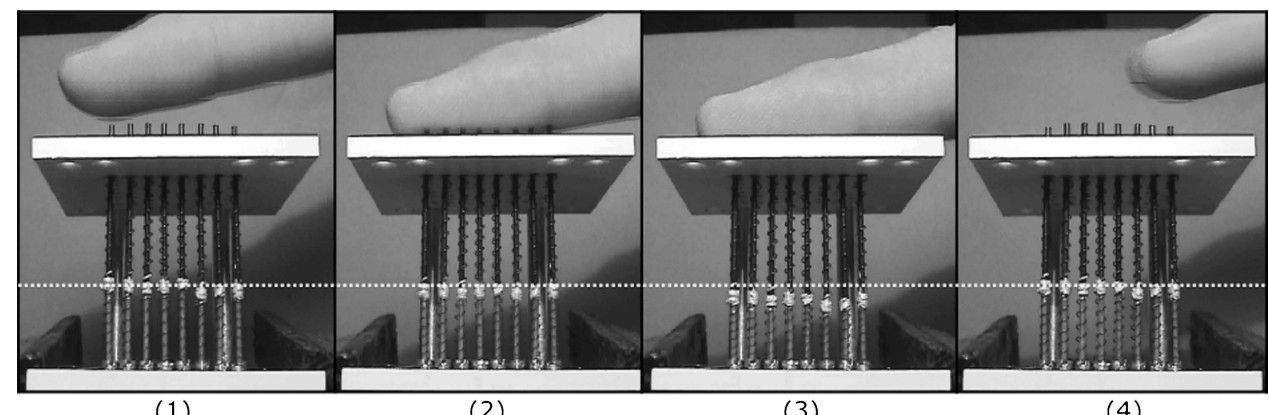

(1)

(2)

(3)

(4)

Figure 10 The taxel's performance: bistable concept with no mechanical blocking structures.
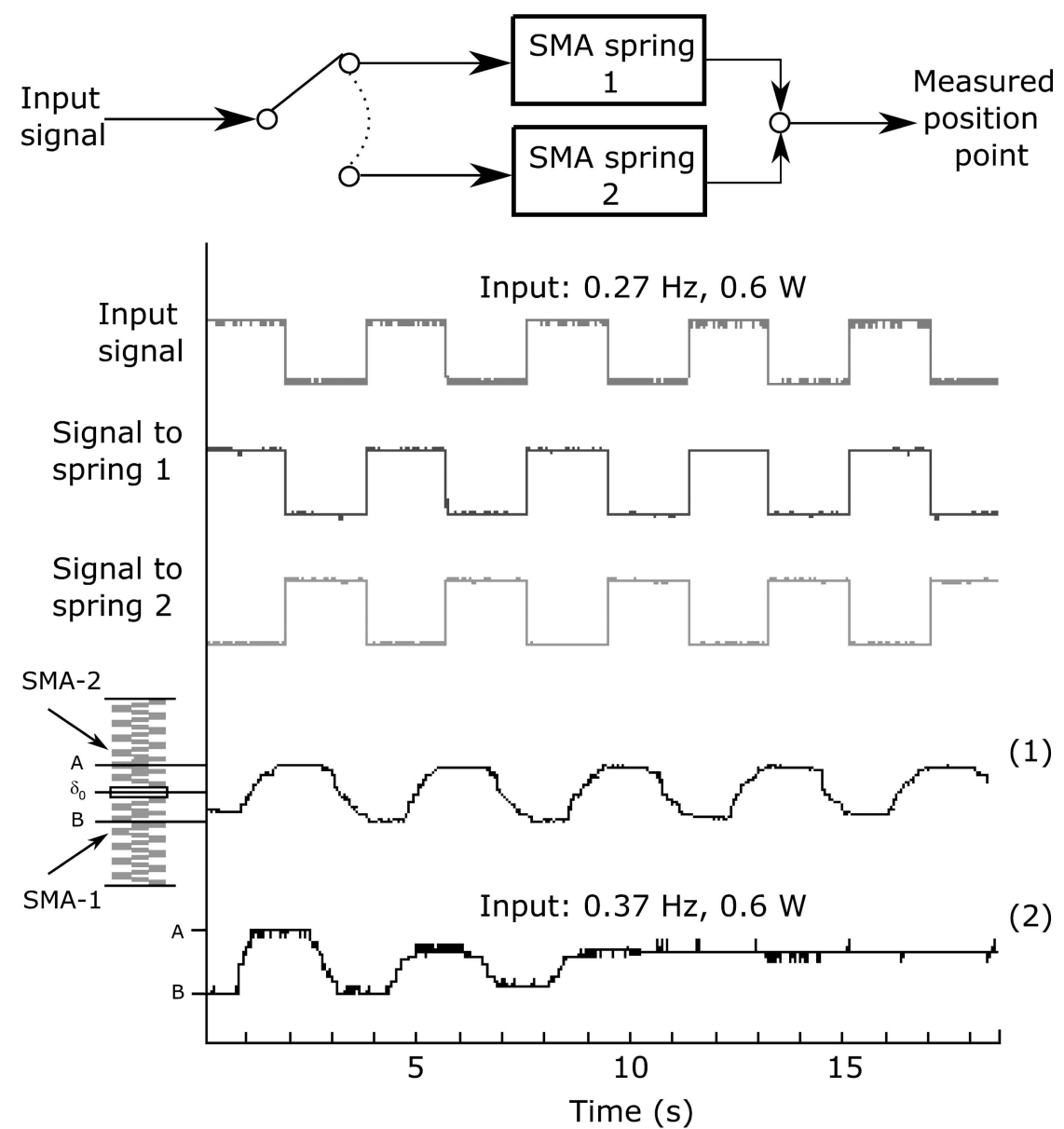

(a)

Figure 11 (a) The antagonist controller and position tracking responses of the actuator to 0.27 and $0.37 \mathrm{~Hz}$ square power signals. (b) Tracking responses to $0.5,1$ and $1.5 \mathrm{~Hz}$ square power signals under forced-air convection conditions.

the surrounding medium. This limitation requires the use of different strategies for increasing the cooling rate.

Several approaches (Wellman et al. 1997; Russell and Gorbet 1995) have suggested the use of water and heat sinking mechanisms as coolants. It has to be recognized that these methods have shown the most promising results. However, an actuator immersed in constant recirculating water and additional mechanisms complicate the actuator's design and hardly imply a fully portable, lightweight and compact tactile display.
To keep the actuator's simplicity, forced-air convection provided by a simple and inexpensive computer minifan was used as cooling system. Figure 11(b) shows the modified experimental set-up and tracking response of the antagonist actuator, under no load conditions, to $0.5,1$ and $1.5 \mathrm{~Hz}$ square power signals. Note that the actuator's bandwidth increases up to $1.5 \mathrm{~Hz}$ without saturation using forced-air convection. However, power increases as well in order to accelerate the heating rate and ensure the taxel's total stroke (distance $A-B$ in Figure 11(a)). 

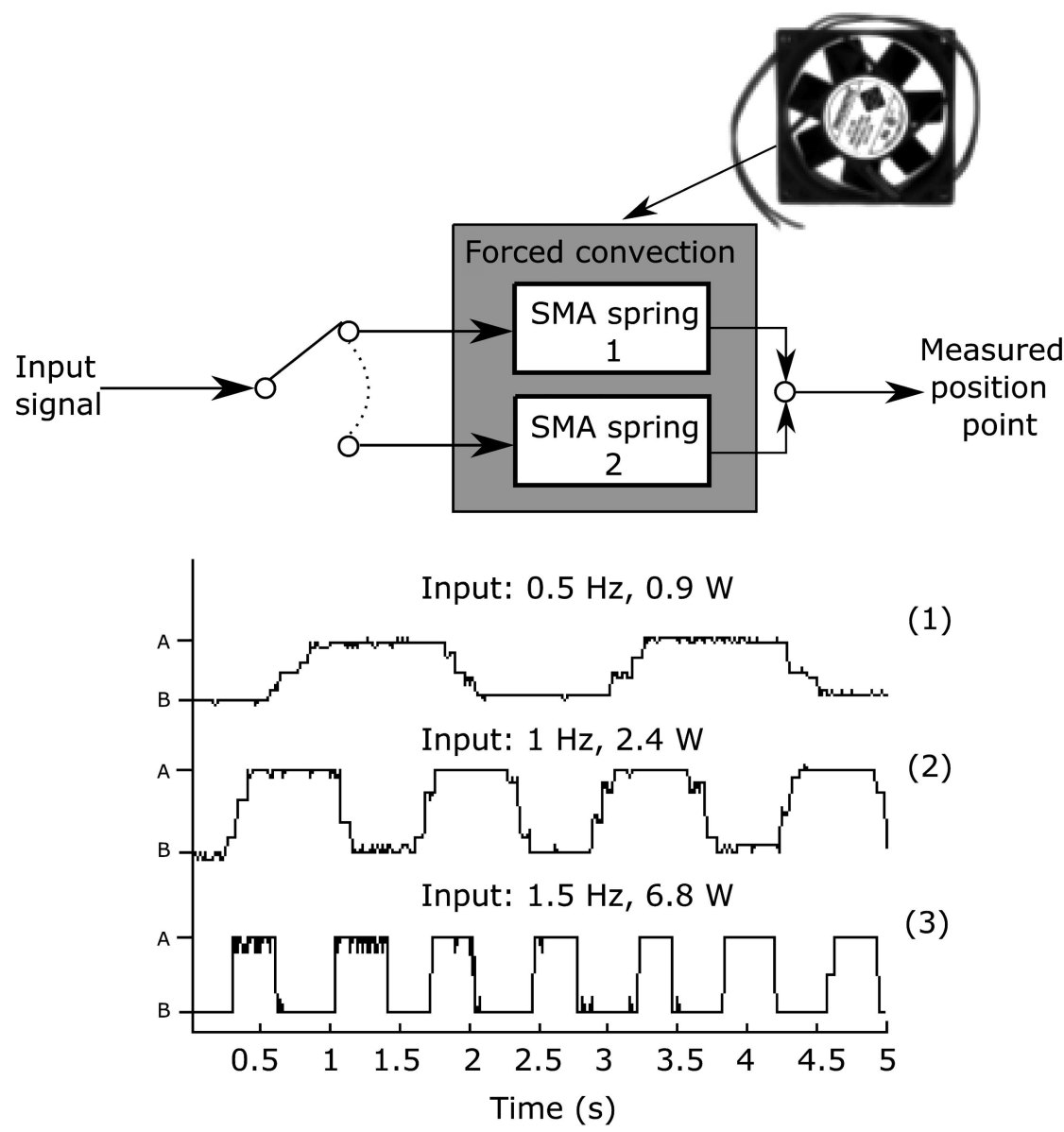

(1)

(b)

Figure 11 Continued

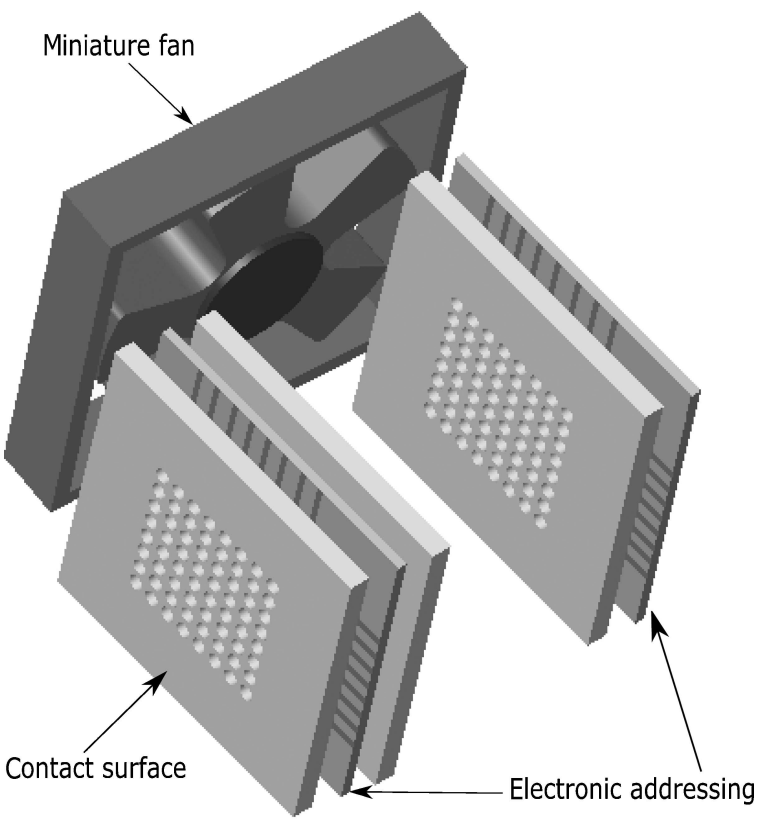

(a)

Figure 12 (a) Conceptual representation of an $8 \times 8$ SMA based tactile display and (b) first prototype.

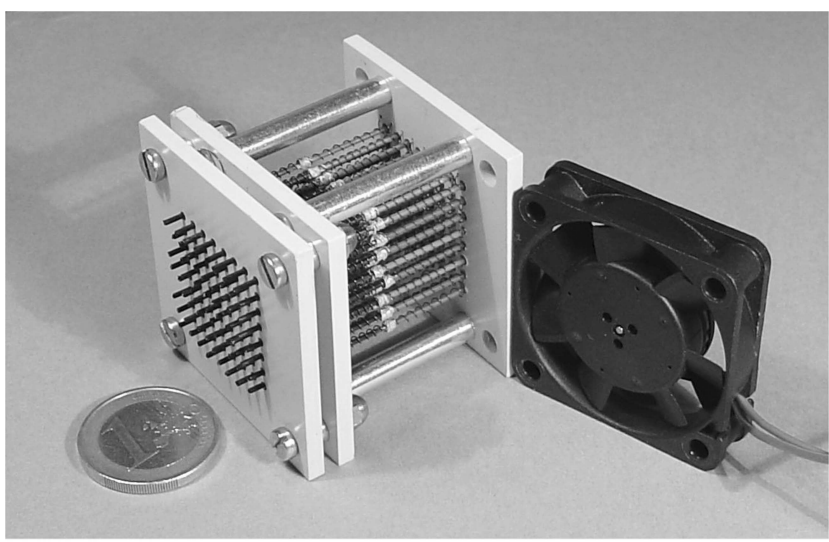

(b)

Figure 12 Continued

Summarizing, the main advantages of this concept of actuator are:

- The simplicity of design and ease of implementation.

- The simplicity of control: taxel totally raised or totally retracted. Each spring may take either the austenite (high 


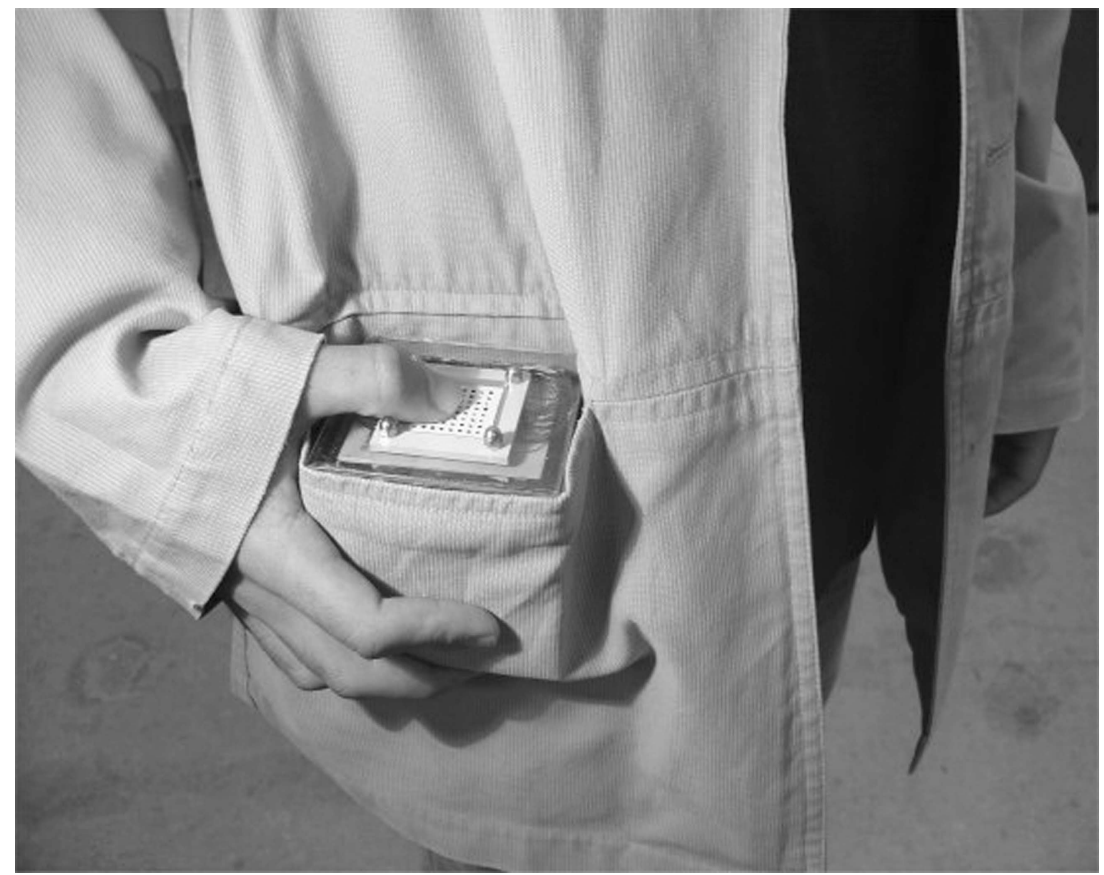

Figure 13 The full tactile display.

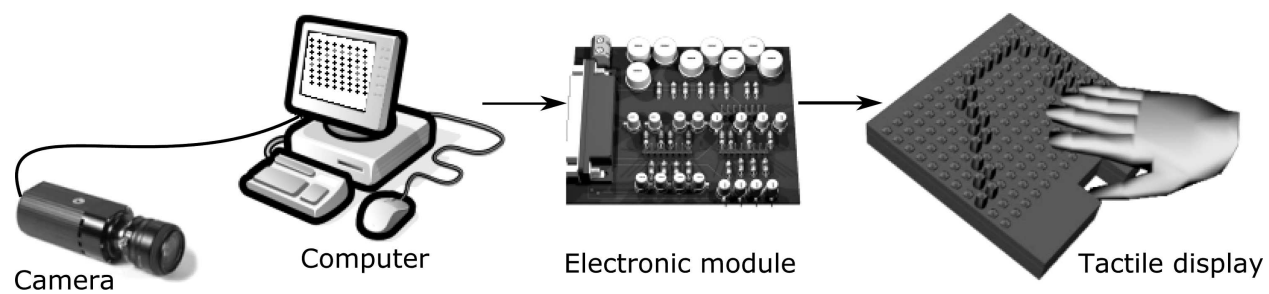

Figure 14 Drive components of the tactile display.

temperature and contracted) state or the martensite (low temperature and stretched) state, and nothing in between.

- A symmetric dynamic behavior (as both SMA springs are identical).

- The actuator needs only energy when changing from one state to the other and no miniature mechanical blocking structures are needed to keep the taxel active. Lower and higher positions are ensured by the mechanical characteristics of the SMA springs.

- Its low cost.

\section{TACTILE DISPLAY}

\section{Design}

Based on this approach of actuation, a conceptual representation of a tactile display is proposed in Figure 12(a). A first prototype of $8 \times 8$ tactile elements was envisaged. It consists of three plates that assemble the 64 taxels. The taxels are to be independently addressed, electrically heated and cooled using forced-air convection provided by a mini-fan placed right next to the plates.

\section{Prototype}

Figure 12(b) shows the taxel array fully assembled (Velazquez et al. 2006b). Summarizing its key features, this first prototype consists of a 64-element array spaced $2.6 \mathrm{~mm}$ apart (within Braille standard) that vertically actuates SMA based miniature actuators of $1.5 \mathrm{~mm}$ diameter to a height range of $1.4 \mathrm{~mm}$ with a pull force of $300 \mathrm{mN}$ up to a $1.5 \mathrm{~Hz}$ bandwidth.

The full display weighs $200 \mathrm{~g}$ and its compact dimensions (a cube of $8 \mathrm{~cm}$ side-length) make it easily carried by the user (Figure 13).

Its laboratory cost is only 200 USD and with industrial mass production, a much lower price can definitively be expected. A wide range of applications can then be envisaged: from an affordable-to-everyone tactile display to a disposable device.

\section{Electronic drive}

Figure 14 shows a schematic representation of the electronic system used to drive the tactile display. The system consists of a user friendly software interface that generates tactile data (such as shapes, pictures, patterns, sequences, etc.) or that receives data from an external device (such 


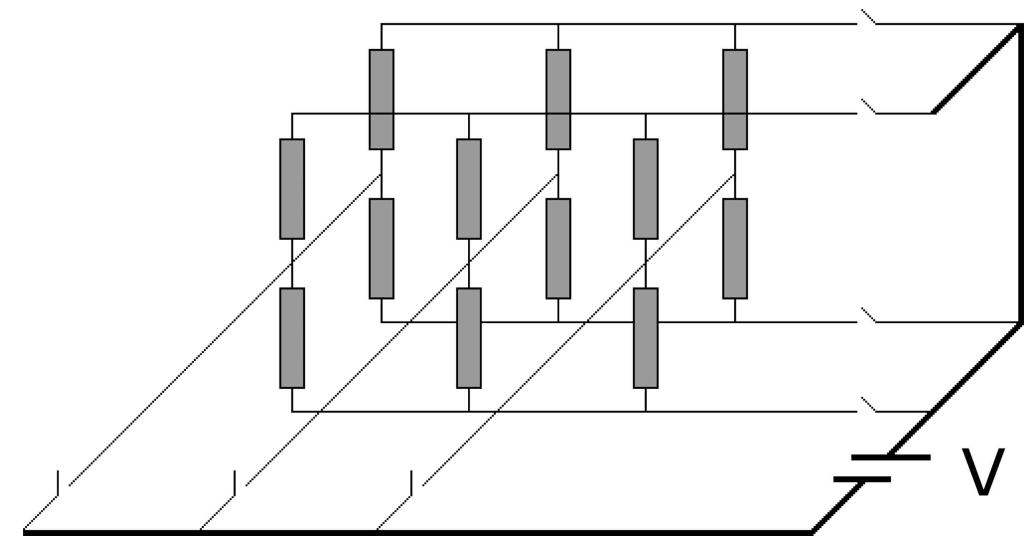

Figure 15 3M crossbar matrix switch control method: an SMA spring is actuated by placing its row to $V$ and the corresponding column to GND.

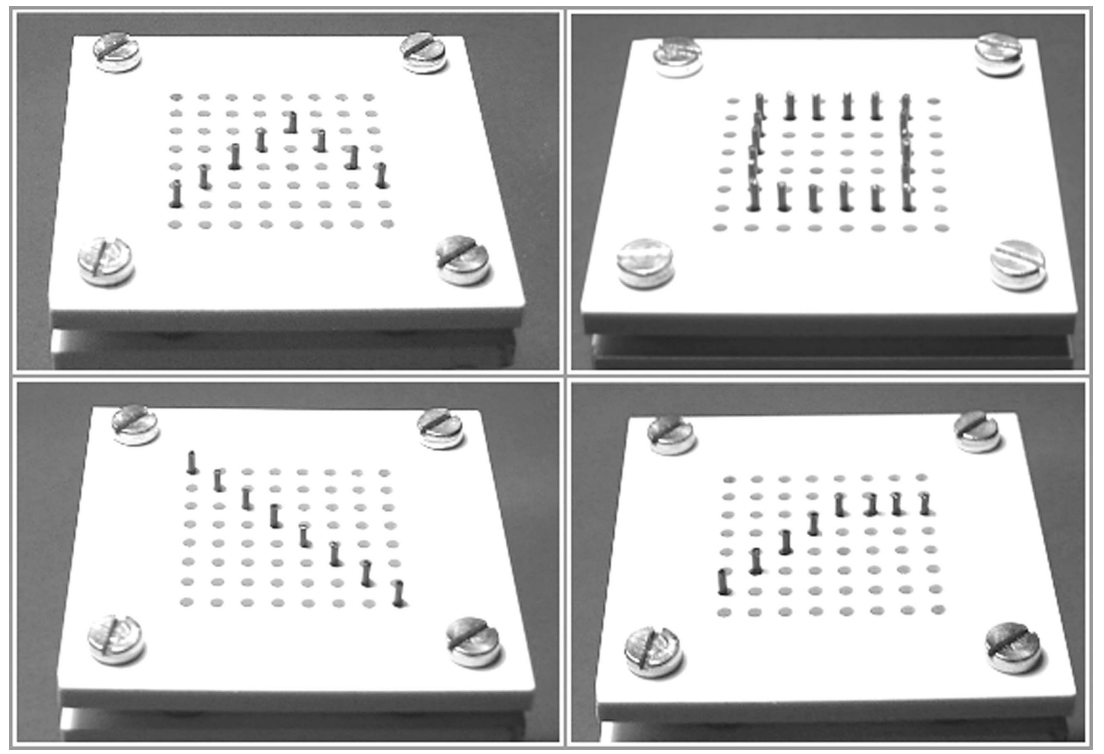

Figure 16 Examples of 2D tactile shapes displayed using the tactile device.

as a camera system). Using RS232 protocol, the computer transmits this information to an electronic module, where a controller interprets the command strings and sets the position (up or down) of each taxel of the display (Velazquez et al. 2006b).

An important issue that must be addressed in electronic control systems for matrix displays is the scalability problem. A typical $M \times M$ matrix in which each element is controlled independently requires an amount of $\mathrm{M}^{2}$ control circuitry. Such controllers work perfectly well if $M$ is small. However, as the size of the matrix increases, the number of control elements quickly becomes very large.

Since the tactile display consists of 64 taxels, $128 \mathrm{SMA}$ springs are needed to be controlled. A burdensome control scheme of $2 \mathrm{M}^{2}$ is required to activate independently the 64 taxels.

A more convenient and cost-effective method of implementing an electronic drive for large-scale matrix displays is the crossbar method.
Figure 15 shows the crossbar method adopted to drive the tactile display. Closing a switch at the appropriate cross-point actuates the desired SMA spring. Note that the control scheme reduces from $2 \mathrm{M}^{2}$ to $3 \mathrm{M}$. This design also intends to produce compact electronic boards so that they could be embedded in the same tactile display structure.

\section{Tactile shapes}

Figure 16 shows different examples of 2D tactile shapes displayed using the tactile system. Note that this concept opens the possibility of expanding Braille text displays to text-graphics displays using the same device.

\section{Preliminary results on tactile shape recognition}

Preliminary shape recognition tests were carried out to investigate the performance of the tactile display. Five healthy sighted voluntary subjects participated in the tests. All subjects were right-handed males with an average age 


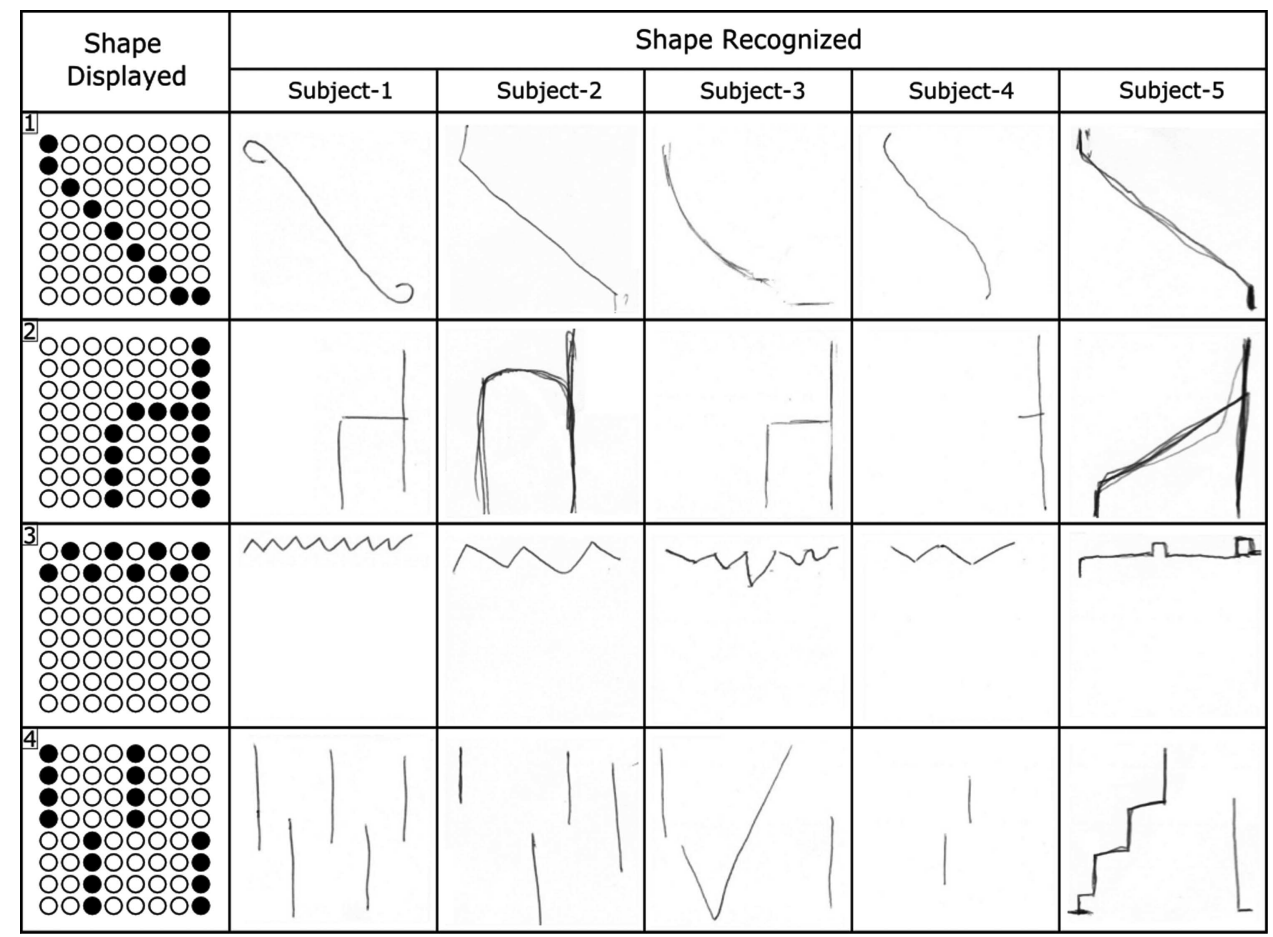

Figure 17 Results of the five subjects in the $2 \mathrm{D}$ tactile shape recognition task.

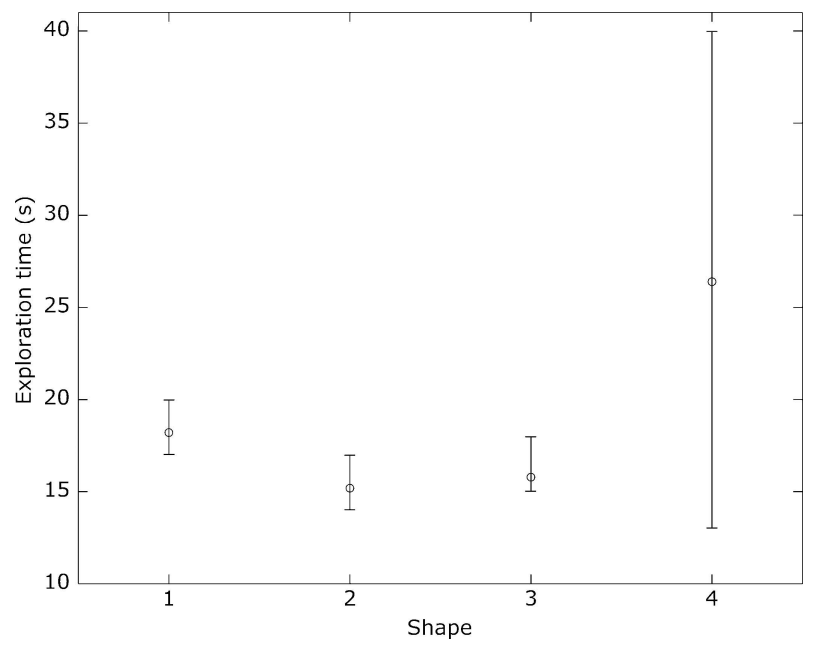

Figure 18 Exploration time by shape.

of 26 years and with absolutely no previous experience in Braille or tactile display usage. During the experiments, the subjects were sat blindfolded in front of the tactile display. They were asked to explore freely the tactile surface (no time restriction and no specific finger/hand imposed) and then asked to draw on a sheet of paper the shape perceived. Each recognition task was timed.

Figure 17 summarizes the results obtained: it shows the shape displayed on the tactile display and the timed shapes drawn by each subject. Note that the shape recognized is quite close to the displayed.

Figure 18 shows the exploration times by shape (maximum, minimum and average time). Note that the time needed to recognize each shape is roughly the same for all subjects. Results suggest either a higher difficulty in recognizing the fourth shape or fatigue since two subjects took up to $40 \mathrm{~s}$ exploring the tactile display.

Future work will involve more formal psychophysics experiments especially those concerned with space organization and space cognitive maps. However, these preliminary results on simple shapes obtained from healthy-sighted totally naive in Braille/tactile display usage are undoubtedly encouraging for testing the system with blind people.

\section{CONCLUSION}

This paper has presented a new low-cost, lightweight, compact and highly portable tactile display. Using alternative technologies like SMAs, this concept intends to make possible highly portable text-graphic Braille-like displays for 200 USD or less.

A first prototype of 64 SMA based taxels has been introduced. This system offers high spatial resolution and good performance in addition to being robust, maintainable and simple to fabricate. Both mechanical and electronic drive designs are easily scalable with respect to the number of pins while still being price attractive.

A miniature SMA helical spring and actuator have successfully been designed and implemented as actuating elements of the tactile display. A combined computationalexperimental study on the thermomechanical properties of both SMA active element and actuator has been presented to characterize the actuator's antagonist type behavior and to show the advantages of its no-blocking structures 
concept and overall performance for touch stimulation applications.

A set of preliminary shape recognition experiments was presented to show the effectiveness of the tactile information transmitted through the display in sighted people. Future experiments on blind voluntary subjects are currently being performed and are expected to demonstrate initial feasibility of the system.

\section{REFERENCES}

Benali-Khoudja M, Hafez M, Alexandre JM, Kheddar A, Moreau V. 2004. VITAL: A new low-cost VIbro-TActiLe display system. In Proceedings of IEEE International Conference on Robotics and Automation, New Orleans, USA, pp.721-726.

Brenner W, Mitic S, Vujanic A, Popovic G. 2000. Micro-actuation principles for high resolution graphic tactile displays. In Proceedings of 7 th International Conference on New Actuators Bremen, Germany, pp. 567-570.

Featherstone R, Teh H. 2004. Improving the speed of SMA actuators by faster electrical heating. In Proceedings of International Symposium on Experimental Robotics Singapore.

Geiger S. 1984. Handbook of Physiology Section 1: The Nervous System. American Physiological Society, Bethesda, MD, USA.

HumanWare Inc. 2007, updated information available at: www.humanware.com. (accessed 10/2/07)

Konyo M, Tadokoro S, Takamori T. 2000. Artificial tactile feel display using soft gel actuators. In Proceedings of IEEE International Conference on Robotics and Automation, San Francisco, USA, pp. 3416-3421.

Loomis J. 1981. On the tangibility of letters and Braille. Perception Psychophys, 29(1), 37-46.

Moy G, Wagner C, Fearing R. 2002. A compliant tactile display for teletaction. In Proceedings of IEEE International Conference on Robotics and Automation, Piscataway, USA, pp. 3409-3415.

NFB: National Federation for the Blind 2007, updated information available at: http://nfb.org. (accessed 10/2/07)

Pasquero J, Hayward V, 2003. STReSS: A practical tactile display system with one millimeter spatial resolution and $700 \mathrm{~Hz}$ refresh rate. In Proceedings of Eurohaptics 2003, Dublin Ireland, pp. 94-110.

Russell R, Gorbet R. 1995. Improving the response of SMA actuators. In Proceedings of IEEE International Conference on Robotics and Automation Nagoya, Japan, pp. 2299-2304.

Sekuler R, Blake R. 2002. Perception. New York: McGraw-Hill Education.

Taylor P, Moser A, Creed A. 1997. The design and control of a tactile display based on shape memory alloys. In Proceedings of IEEE International Conference on Robotics and Automation, Albuquerque. USA, pp. 1318-1323.

Taylor P, Pollet D, Hosseini A, Varley C. 1998. Advances in an electrorheological fluid based tactile array. Displays, 18, 135-141.

Tobushi H, Tanaka K. 1991. Deformation of a shape memory alloy helical spring. 7SME Int. 7. Series I, 34(1), 83-89.

Velazquez R, Hafez M, Pissaloux E, and Szewczyk J, 2006a. A computational-experimental thermomechanical study of shape memory alloy microcoils and its application to the design of actuators. F. Comput. Theor. Nanosci., 3(4), 538-550.

Velazquez R, Pissaloux E, Wiertlewski M. 2006b. A compact tactile display for the blind with shape memory alloys. In Proceedings of IEEE International Conference on Robotics and Automation, Orlando, USA, pp. 3905-3910.

Velazquez R, Pissaloux E, Hafez M, Szewczyk J. 2005. Miniature shape memory alloy actuator for tactile binary information display. In Proceedings of IEEE International Conference on Robotics and Automation Barcelona, Spain, pp. 13561361.

Vidal F, Madueño M, Navas R. 2005. Thermopneumatic actuator for tactile displays and smart actuation circuitry. In Proceedings of SPIE International Symposium on Microtechnologies for the New Millennium Seville, Spain, pp. 484-492.

Wagner C, Lederman S, Howe R. 2002. A tactile shape display using RC servomotors. In Proceedings of the 10th Symposium on Haptic Interfaces for Virtual Environment and Teleoperator Systems, Orlando, USA, pp. 354-355.

Wellman P, Peine W, Favalora G, Howe R. 1997. Mechanical design and control of a high bandwidth SMA tactile display. In Proceedings of International Symposium on Experimental Robotics Barcelona, Spain, pp. 56-66. 

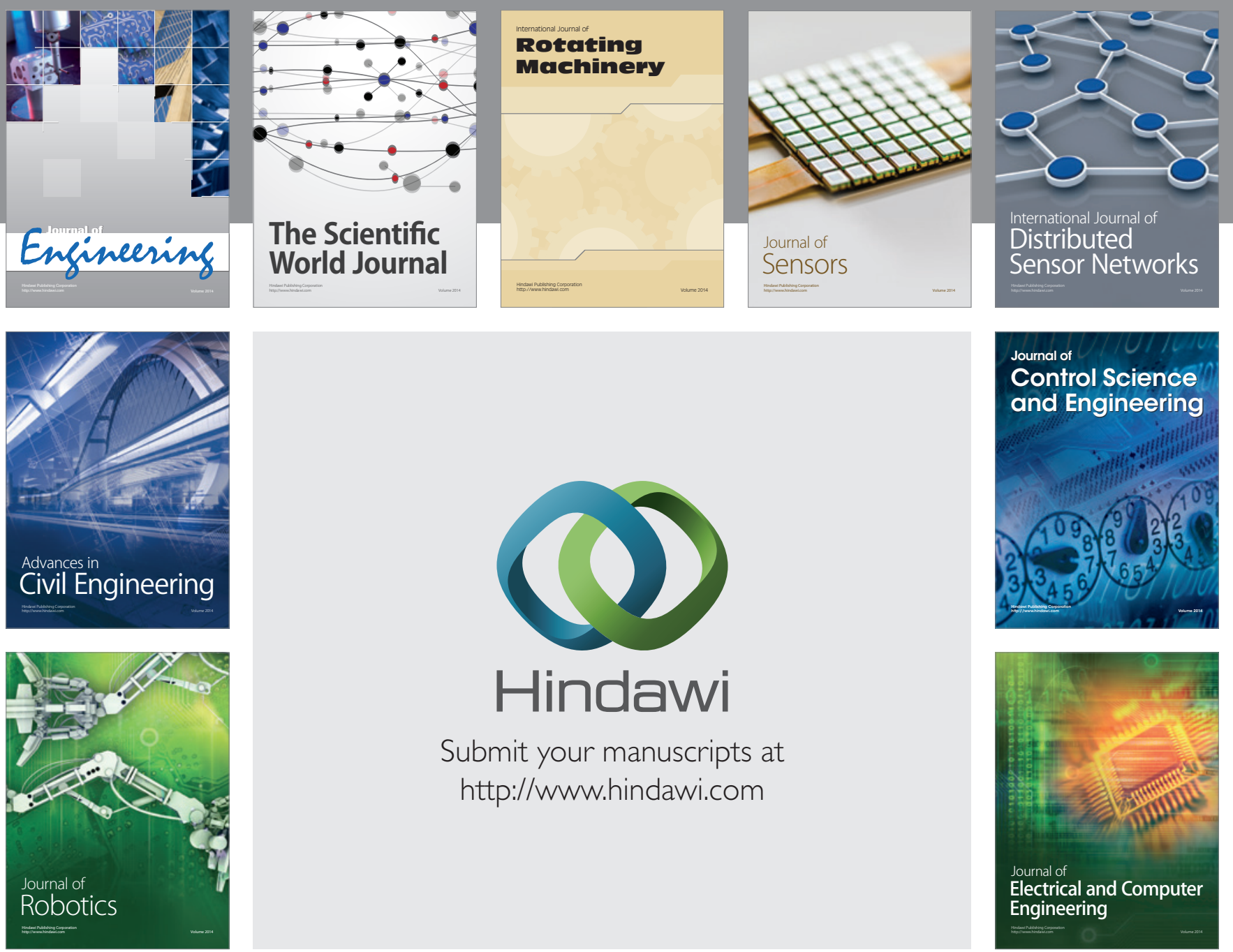

Submit your manuscripts at

http://www.hindawi.com
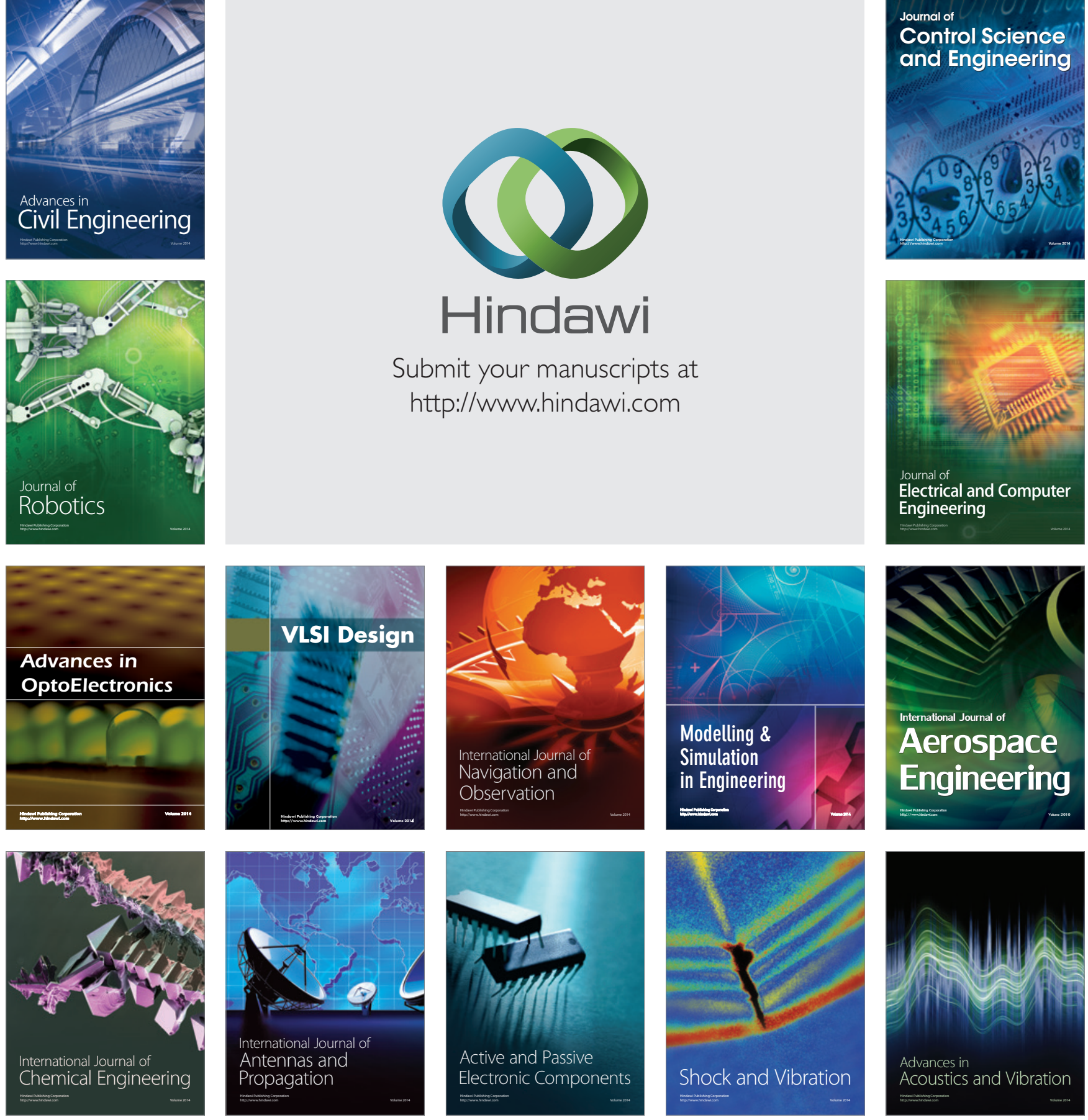